\title{
Intrinsic brainstem glioma mimicking an ependymoma
}

\author{
Manish K. Kasliwal • Deepak Agrawal
}

Received: 14 February 2009 /Revised: 12 March 2009 / Accepted: 1 April 2009 /Published online: 13 May 2009

(C) Springer-Verlag 2009

A 14-year-old child presented with complaints of headache, vomiting and complete vision loss for 1 month. Sagittal T1$\mathrm{W}$ and T2-W MR images of the brain revealed a posterior fossa tumor with cervical spinal canal extension consistent with ependymoma (Fig. 1). Intraoperatively, a moderately vascular intrinsic brainstem glioma was found with a dorsal exophytic component extending into the cervical canal to the $\mathrm{C} 4$ level with a caudal syrinx. Histopathology confirmed the diagnosis of pilocytic astrocytoma.

Direct cervical intramedullary extension of a posterior fossa tumor is rare, and ependymoma has the greatest predilection for this pattern of spread. Leproux et al. [1] reported a case of cystic astrocytoma with spinal extension through the fourth ventricle outlet foramina. Although cervicomedullary glioma forms a distinct entity among brainstem gliomas, a direct intramedullary cervical canal extension of a posterior fossa pilocytic astrocytoma, as described in this case, is extremely unusual. The recognition of such an unusual spread is important, as cervicomedullary variants of brainstem glioma are relatively benign and radical removal is associated with improved survival [2].

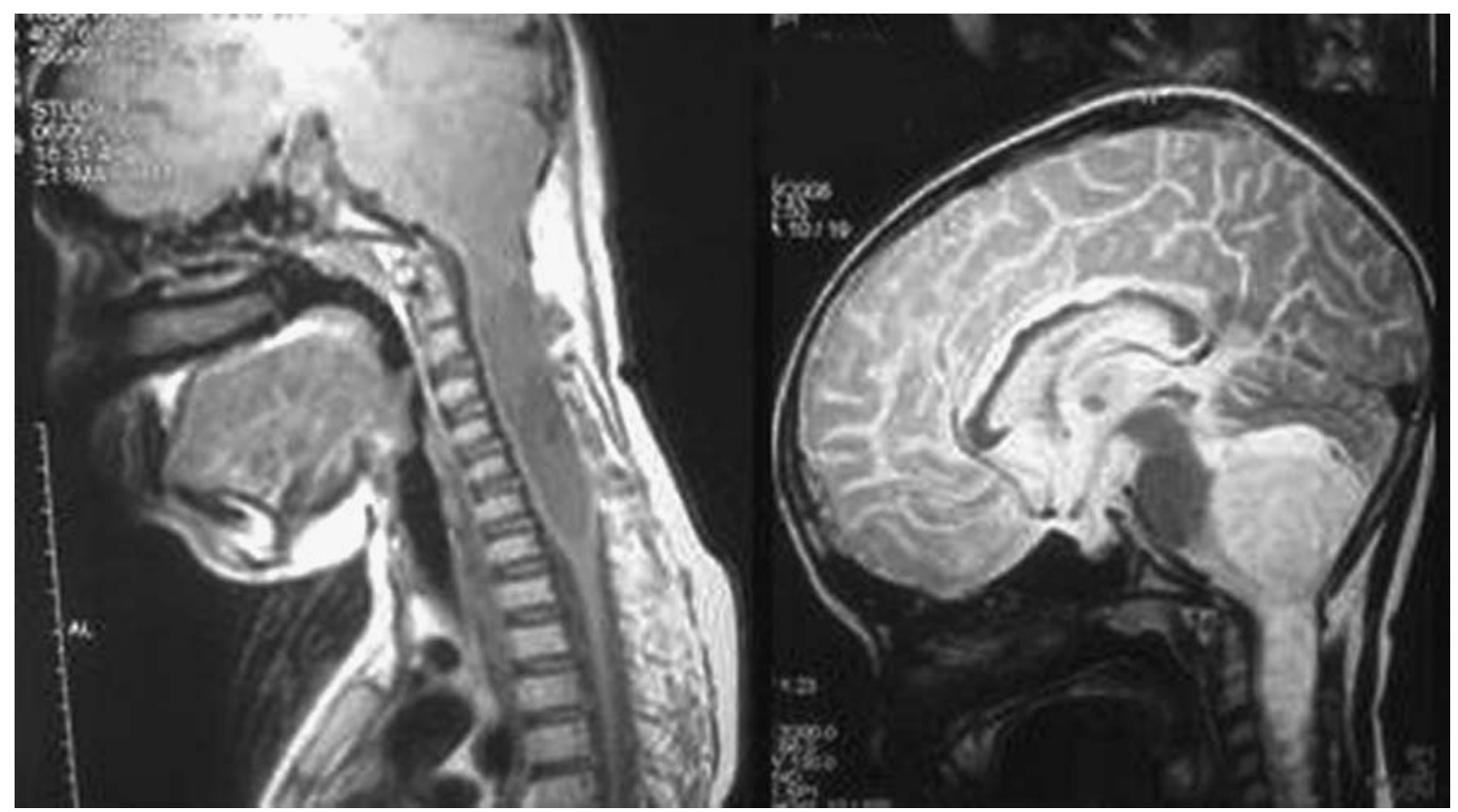

Fig. 1 MR images of the brain and cervical spine

\section{References}

M. K. Kasliwal $(\bowtie) \cdot$ D. Agrawal

Department of Neurosurgery, Neurosciences Centre,

All India Institute of Medical Sciences,

Ansari Nagar, New Delhi, India 110029

e-mail: drdeepak@gmail.com
1. Leproux F, Melançon D, Mercier C et al (1993) Extension of a cerebellar cystic astrocytoma into the cervical canal, demonstrated by magnetic resonance imaging. Can Assoc Radiol J 44:460-462

2. Pablo F, Recinos PF, Sciubba DM et al (2007) Brainstem tumors: where are we today? Pediatr Neurosurg 43:192-201 